\title{
8 Developing the Relational Dimension of Participatory Design Through Creativity-Based Methods
}

\author{
Caoimhe Isha Beaulé, Solen Roth, \\ Anne Marchand and Karine Awashish
}

\section{Introduction}

Mainstream design history often highlights that the discipline's professionalisation emerged primarily from Western institutions after the Industrial Revolution. The dominant discourses in design (e.g. the fields of product design, service design and strategic design) characterise its value as a strategic tool for innovation and an alternative mindset that uses 'human-centred' and iterative approaches to problem-solving (Brown \& Katz, 2009). As well as for creative problem-solving, designers are recognised for their problem setting and framing methods and their ability to conjure up ideas about 'what might be' (Dorst, 2011, 2019). Such 'design ways' are now being applied to a multitude of areas, ranging from visual communication and product and service development to policy-making (Bason, 2016; Nelson \& Stolterman, 2012). Accordingly, design is a dynamic field that keeps on evolving; novel methods and tools are developed as these new contexts of intervention emerge to proffer the latest opportunities and challenges. In the practice of participatory design (also referred to as co-design or co-creation), designers are required to have specific mindsets and skill sets to navigate a design process that involves multiple stakeholders and participants with diverse backgrounds. However, learning to collaborate is not always part of the foundations of design education, leaving young designers and designer/researchers with very few frameworks for working in participatory projects, even less so when the project involves collaborating with a community where there is a history of settler colonialism.

A critical discourse has been emerging within the design community regarding the dominance of Eurocentric paradigms in the field of design, which leaves 'other ways' of designing on the so-called periphery. As in many other disciplines, the topic of decolonisation in design studies has been developing, which has revealed aspects of participatory design that were previously unacknowledged (see Akama et al., 2019; Janzer \& Weinstein, 2014; Schultz et al., 2018; Tlostanova, 2017; Tunstall, 2013). For example, there is increased attention and criticism in respect to implying the universality of design methods and theories developed on the basis of Western epistemologies. These unconscious assumptions 'persistently locate the other while failing to account for the geographical, historical, and corporal locations of the producers' (Schultz et al., 2018 , p. 91). One needs to be careful when applying theories and methodologies to a context different from the one in which they were developed. Akama et al. (2019) 
strengthened this idea by giving examples of 'design with other names' (p. 11) that stem from personal stories (specifically, Māori, Pākehā and Japanese points of view):

The exemplars we share here powerfully demonstrate how respectful, reciprocal, and relational co-designing is already practiced, and in many cases, is being continually practiced in another name by Māori and Aboriginal peoples, and has been, long before design was coined as a term and a profession in Europe in the twentieth century. Most importantly, this enables us to de-couple design from its modern, industrialized roots so it can be re-situated and re-conceptualized as a method, approach, mindset, and ontology, centrally grounded in respectful, reciprocal relationships.

In this chapter, we aim to discuss the relational dimension of community-based participatory design projects. We propose that using a creativity-based approach-one that draws on art, crafts and design-throughout the collaborative process can be one step towards building more respectful, reciprocal and relational collaborations with the communities we engage with. As stated by Akama et al. (2019), relationality is a fundamental yet often unacknowledged part of collaboration. It is actually the key to being able to balance several worlds in a common project (Escobar, 2018). This is especially important when engaging in a collaboration with historically oppressed or marginalised communities.

The ideas outlined in this chapter are based on insights from a decade-long partnership between designers from the Université de Montréal (UdeM) and Indigenous community members of the Atikamekw Nehirowisiw Nation in Quebec, Canada. We will describe some of the reflections that emerged through our experience as design researchers and collaborators in an intergenerational participatory action research project entitled Tapiskwan. More precisely, we questioned ourselves on the influences and confluences that allowed us to investigate the 'colonial' or 'decolonial' approach in the Tapiskwan initiative. Our reflections for this chapter were guided by the following question: What has the Tapiskwan project taught us on the role creativity-based methods can play in developing meaningful and fruitful relationships when design collaborations involve universities and Indigenous communities? We propose that certain kinds of creativity-based methods offer particularly relevant avenues to challenge some of the dominant world views and top-down hierarchies inherent in Western academic frameworks. Given the wickedness of addressing the challenges that are generally approached through a decolonising perspective, in the following sections, we will not be presenting an example of a 'decolonised project' or even a 'decolonial approach'. Rather, we aim to contribute to the discussion by sharing some reflections that emerged from our own hands-on experience in the Tapiskwan project.

We will first situate our chapter in relation to the decolonising theme of this book and how it relates to the specific practice of participatory design. An overview of collaborative design processes will follow, whereby we locate the relational dimension of a participatory design process. We will then conceptualise what we mean by 'creativity-based methods' and the relevance for designer/researchers to expand their frameworks to include activities associated with craft and art when working in community-based participatory projects. Finally, we will share some insights on these themes that emerged from our experience as collaborators in the Tapiskwan 
project. These exchanges raised new perspectives regarding approaches to decolonisation from economic, institutional and multicultural perspectives.

\section{Participatory Design and Decolonisation}

Community-based participatory design projects increasingly involve academic-community partnerships. While the intent is often to provide a framework for good working relationships, such partnerships can inadvertently impose hierarchies amongst partners that can be manifested through tensions concerning the very premises of these new collaborations. There is an added challenge when partners come from different cultures, which is compounded even further when these cultures have a shared colonial history, as is often the case for collaborations involving Indigenous partners. Whether intentional or not, the involvement of designer/researchers is frequently driven by the dominant paradigm in which they are located. These issues should be explicitly addressed in the foundations of design education, as stated by Akama et al. (2019):

With the exception of [Participatory Design] and research training in academic domains, traditional design education (including design thinking) has not paid much attention to the relational or ethical aspects of designing with people. Questions of power, decision making, reciprocity, or responsibility are often left untouched. This has resulted in a significant gap in teaching and self-training in design. This is no longer acceptable.

The link between design and colonialism exists on many levels; for instance, when non-Western crafts are arbitrarily set apart from Western 'modern' design, when local forms of innovation go unacknowledged or when Western forms of innovation are portrayed as the ideal (Tunstall, 2013). This seemingly justifies the 'intervention' of Western designers in non-Western contexts. In addition to the hierarchies that are already embedded in Western research and academia in general, these additional tensions can have profound impacts on the researcher/designer-participant relationships, and ultimately, on the outcomes and success of these intercultural collaborations. Further, by focusing primarily on the process (e.g. tools and methods) of a collaborative project rather than its outcomes, one can do more harm than good. A communitybased project that ends while still in the prototype phase, if designers leave before doing their part in the implementation phase, can greatly diminish the positive impacts on the community involved (Tunstall, 2013). From this perspective, community-based projects must arguably 'shift [their] focus from one that is user-centred to one that is situation-centred' (Janzer \& Weinstein, 2014, p. 327), which requires a deep understanding of the situation in question. Outsiders designing in and for situations that they do not fully understand can lead to particularly 'risky cultural bias' (p. 341).

Discussing decolonising practices in the context of design is complex, and shifting the paradigm on the ground is difficult, yet extremely important. Based on our experience as designer/researchers and collaborators in a project involving Indigenous partners, we see these reflections as being essential. Indeed, Indigenous peoples often come to these new projects with the baggage of previous negative experiences working with social scientists, biologists and health researchers within a colonial approach (Kovach, 2010; Smith, 2012). Designer/researchers cannot ignore the fact that they have inherited and, in some cases, contributed to the colonial dynamic that exists between these 
communities and universities. And yet, even those who are aware of this history and do not wish to reproduce it are not always well equipped to shift their practice towards more decolonial approaches. In that regard, an increasing number of academics have cited 'decolonisation' as one of their objectives, prompting Tuck and Yang (2012) to remind us that this is not merely a 'metaphor'. Simply put, true decolonisation cannot occur without the repatriation of Indigenous land and life. Therefore, we use this term carefully, however, at the same time, take a cue from Ho-Chunk scholar Amy Lonetree's (2012) claim that 'Decolonising is powerful not only because it ends and mends harms, but also because it opens opportunities. ... Sites of oppression have the potential to transform into sites of revitalisation and autonomy' (p. 173).

\section{The Relational Dimension of Participatory Design}

Using design in participatory contexts is not new, as the practice has been around for about 50 years and is typically referred to as participatory design, or co-creation and co-design in more recent terminology (Sanders \& Stappers, 2008). As mentioned previously, we direct our attention to the relational work that is not typically acknowledged in participatory design processes. We argue, along with Akama et al. (2019), that this crucial and often invisible layer is a key component of successful communitybased participatory design projects (see Figure 8.1). We need to add that the relational

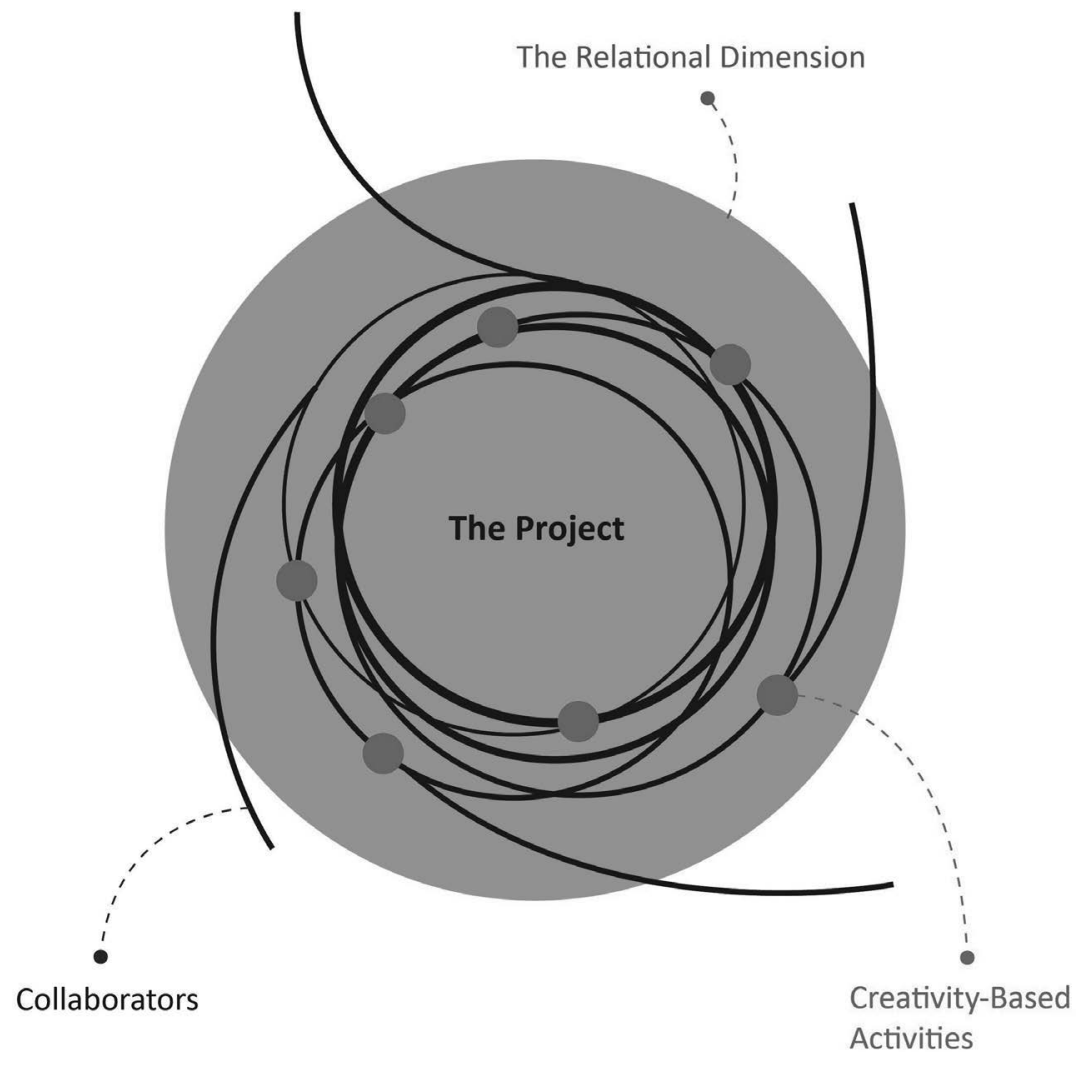

Figure 8.1 Situating the relational dimension of community-based participatory design.

Source: Figure by the authors, 2020 
dimension is always present throughout a collaboration. Although it is not often explicitly discussed, it affects a project in many ways: ensuring good communication, making participants feel valued, helping establish fruitful collaborations and potentially challenging arbitrary and ethnocentric hierarchies.

Different ways to visually represent this collaborative course of action have been used to communicate the core principles of 'design thinking' to various audiences. One of the most common visual representations of the design process is the UK Design Council's 'Double Diamond' (DD) model (Design Council UK, 2005). The two diamond shapes in the DD model represent the way designers move between diverging and converging phases in a design process, moving from problem framing and ideation to solution development and implementation. Designers around the world use this model to communicate their creative processes, most typically for product, service and strategic design fields. However, in participatory contexts, Akama et al. (2019) criticised the use of the DD model and, in fact, any type of replicable model, as they are seen as inadequate for depicting a design process in collaborative settings. The authors argued the danger of using such perpetuating colonial ways when using 'problem-solving, replicable methods and outcomes' (p. 1) stating, as an example, that the DD model 'must sit alongside any number of design expressions, and not displace, disembody, or dislocate design from the sites in which it lives' (p. 23).

Ironically, we almost used the DD model to situate the relational dimension of collaborative design in this chapter. In our discussions, we realised that our practical experience in the Tapiskwan project did not correspond to this at all. Even though we can relate to popular models such as the DD on a micro level (e.g. product development), it does not reflect our experience on the structural level of a community-based participatory design project. Based on our hands-on experience, we agree with Akama et al. (2019) that participatory design processes are difficult to illustrate because they are unique to the contexts in which they operate and the participating individuals, and how they actively are shaping the process. In participatory design practices, Sanders and Stappers (2008) characterised the first stages as being fuzzy, chaotic, filled with ambiguity and confined to open-ended questions. We characterise community-based participatory design processes as being messy, chaotic (not only in the initial phase), organically constructed and not having a clean-cut end (broadly illustrated in Figure 8.1).

The next section gives an overview on how particular kinds of creativity-based methods (at the intersection of art, design and craft) can create a setting that is favourable to collaboration and to the development of relationships of mutual understanding and trust amongst project collaborators.

\section{Creativity-Based Methods for Participatory Engagement}

Although not yet a common practice in mainstream participatory design workshops, nor in design research in general, arts-based research methods can be seen as a valuable set of approaches for designers and researchers working in community-based projects. Arts-based research perceives art as a way of knowing (Leavy, 2018) and allows 'important social and cultural issues ... to be seen in a previously unavailable light' (Barone \& Eisner, 2011, p. 122). The forms of artistic practices one can engage in are endless, ranging from literary forms (e.g. essays or poetry), performance (e.g. music, dance or theatre), visual arts (e.g. photography, drawing, installations or sculpture), audio-visual forms (e.g. film and video) or combined multiple forms of artistic 
expression (Leavy, 2018, p. 4). The use of methods that draw on artistic expression in the design process already exists, particularly in the 'discovering phase' and in usercentred mindsets. For example, the use of cultural probes (e.g. packages with cameras, maps, postcards, paper and pens) are used to stimulate the participants' imagination (see Gaver et al., 1999). Arts-based methods are also a gateway to different kinds of information, in contrast to what can be expressed through writing and speech only. They allow individuals to express themselves in a different way than with words; the possibilities are extremely varied. Each activity should be selected to match the specific project's characteristics, including the overarching objectives, the participants' profiles and the available resources and expertise.

Art and design research conducted by teams in the Arctic region of Finland has strengthened the relevance of intersecting artistic, design and craft practices when working in community-based projects. The latter has shown that a more holistic approach is a better fit for the context circumpolar communities, where these different practices are not often considered as discrete entities as they are in Western institutions. For example, Indigenous concepts such as Sámi Duodji, or handicraft, encapsulate a more holistic understanding of the practices of 'making', which intersect not only art, design and craft, but do not separate the spiritual and physical worlds (Guttorm, 2015; Jokela et al., 2019). Sámi works that are handmade 'carry in them knowledge about the past, they explain people's relationships to each other, about crafting skills and aesthetic sense' (Guttorm, 2015, p. 64). Similarly, Akama et al. (2019) have reminded us that design exists in many other cultures: "designs with other names", including a variety of skills, spaces, artifacts, practices, instruments, representations, knowledges, and ontologies, that are embedded in these everyday environments can enhance an intimacy of interrelatedness "in-between" . . . beings and non-beings' (p. 11).

Along the same line of thought, researchers in the participatory field of service design have also been combining methods from art, design and crafts into various design projects. Mäkiranta and Ylitapio-Mäntylä (2019) highlighted the importance of paying constant attention to the complex ethical issues regarding participatory design research projects with Indigenous communities and have discussed the researcher/designer-participant relationships that emerge within these collaborations. The authors stress the importance of having community members participate in the workshop planning in order to avoid redoing the work on-site to adapt it to the cultural context of the local community. As part of this process, activities that enable cultural exchanges which help build researcher/designer-participant relationships are deemed essential in order to acknowledge different ways of knowing, but also to identify similarities amongst epistemologies (Mäkiranta \& Ylitapio-Mäntylä, 2019). We have had similar experiences. Moreover, in contrast to choosing Western methods and tools by default, they emphasised that it is important to prioritise ones that are familiar to community members. The Tapiskwan project provides many examples of this.

Indeed, decentring Western concepts and world views to make room for those of the participating communities is not only good practice from the point of view of intercultural relationships; this practice is also one of several key tenets of decolonisation efforts, another one being the full participation of communities. As Roth (2019) has argued previously, when non-Indigenous people attempt a transformation in the realm of values and concepts without the active participation of those whose values and concepts they use, then the process is arguably more appropriative than it is 
decolonial. In some cases, it can even amount to what has been defined as 'cognitive imperialism' (Battiste \& Youngblood Henderson, 2000, p. 12). This is one of the reasons why, if creativity-based methods are to be used as part of decolonisation efforts, they must also be combined with participatory approaches as well as encompass fundamentally different logics (Tlostanova, 2017).

These critical reflections are relevant regarding the way in which participatory design (as taught in Western education) could benefit from expanding its frameworks and blurring the borders amongst art, design and crafts, especially when collaborating in intercultural contexts with Indigenous communities or other contexts located outside of the 'mainstream'. In respect to the idea of developing the relational dimension of participatory design, artistic methods can enable empathy and cultural exchanges and leave room for a multiplicity of views and ways of knowing (Leavy, 2015; Miettinen et al., 2016) to collaboratively build a design process. Creativity-based methods could also allow more horizontal sharing in the initial stages of a project. Designers and designer/researchers working in community-based participatory settings could develop their own creativity-based research methodologies when engaging with communities, as opposed to using social science research methods by default (e.g. interviews, focus groups, participant observations) or replicating design methods that are taken out of context. While these commonly used methods can prove useful, they may set the stage for a researcher-researched relationship that is not always conducive to creating trust from the outset-and may result in quite the opposite of what was intended.

In Quebec, Canada, the Design et Culture Matérielle (Design and Material Culture $[\mathrm{DCM}])$ group has been working with creativity-based methods that foster empowerment and knowledge transfer amongst Indigenous peoples for over two decades. In the next section of this chapter, we draw on some of our insights as researchers, designers and collaborators concerning one DCM project, Tapiskwan, an intergenerational participatory action research partnership between the UdeM design school and the Conseil de la Nation Atikamekw (Atikamekw Nation Council [CNA]). We discuss some of the creativity-based methods employed, how they benefited the collaborative process even as challenges emerged, and the importance these methods had with respect to the relational dimension of the project.

\section{Insights From the Tapiskwan Project}

As we previously noted, community-based participatory design projects can greatly benefit from the integration of creativity-based methods (in art, design and crafts). Especially when used early in the process, they have great potential for identifying skill sets and expertise amongst participants and collaboratively building an organic design process that is unique to the project's context.

\section{The Tapiskwan Project}

The Atikamekw Nehirowisiw Nation is one of 11 Indigenous nations whose traditional territories, called Nitaskinan in the Atikamekw language, are located in the Canadian province of Quebec. The majority of the Nation's members live in the three communities of Wemotaci, Manawan and Opitciwan, and they are regrouped politically under the CNA. The Atikamekw were traditionally semi-nomadic people who 
roamed the vast territory of the Mauricie and Lanaudière regions (Gélinas, 2003). Many Atikamekw still practise hunting, fishing and foraging alongside most aspects of contemporary life in Canada (Lamothe, 1999). Nonetheless, like the situation that face Indigenous communities across Canada, the Atikamekw way of life has been fundamentally transformed in the twentieth century by the creation of reserves. These miniscule portions of land forced a mostly sedentary lifestyle upon the communities. The construction of railways and hydroelectric dams and clear-cutting has also contributed to these transformations (Marchand et al., 2018). Further, a specific Canadian residential school system was developed to consciously assimilate Indigenous nations and erase their rich cultures (Truth \& Reconciliation Commission of Canada, 2015). Still, the Atikamekw remain very active in the making of handicrafts, especially in the making of bark objects, one special skill of the Nation's craftsmanship which is a product of traditional know-how (Awashish, 2013). This context framed the focus of the Tapiskwan project towards the development of workshops that were aimed principally towards intergenerational knowledge sharing and empowerment through creative activities (i.e. art, design and crafts).

The university-community partnership was initiated in 2011 when the design school was approached to work with Atikamekw artists and craftspeople who wanted to develop a new range of products inspired by their cultural heritage. The general methodology used over the years is based on work done by La Boîte Rouge Vif, an Indigenous organisation that is affiliated with the University du Québec à Chicoutimi (UQAC) and its research group, the DCM (see Kaine, 2018; Kaine et al., 2010; Kaine et al., 2016). This collaboration led in 2017 to the creation of the Collectif Tapiskwan (Tapiskwan Collective), an Indigenous non-profit organisation (NPO) aiming to value, develop and share Atikamekw art and culture. As of 2019, the project has been managed by the Indigenous-led Coop Nitaskinan (Nitaskinan Cooperative), having transitioned from a university project to a community-centred organisation.

As many actors have been involved in this project, what follows does not summarise the experience of the diverse set of collaborators and participants in the Tapiskwan project, and especially not that of all our Atikamekw partners and collaborators. It reflects our own personal experiences, mostly as members of the design team, all joining the project at different stages of its development. Anne Marchand, who has been part of the research project since the very beginning in 2011, acted as the leader of the UdeM design team. She also became one of the co-founding members of the Tapiskwan Collective in 2017, when the project governance was transferred to a community-based cooperative. Over time, she worked with several designers specialising in product and graphic design. Amongst them was Caoimhe Isha Beaulé, who joined the design team in late 2015. For three years, her principal roles were workshop coordinator and facilitator and graphic designer. In addition to designers, the team included social entrepreneurs and social innovation researchers, as well as an anthropologist, Solen Roth, who joined the UdeM design team in early 2015. Her involvement has focused on the cultural aspects of the project, with most of her activities pertaining to Atikamekw cultural heritage and its perpetuation through creative work. Karine Awashish collaborated in the project at the start, carrying out an action research project on the development of an Atikamekw crafts cooperative coordinated by the CNA (2008-2013); her personal involvement began in 2014. Subsequently, it was through the Nitaskinan Cooperative, which she co-founded in 2015, that the collaboration between UdeM and the CNA continued. Through the Nitaskinan 
Cooperative, she is currently coordinating the Tapiskwan project to ensure administrative and operational sustainability.

\section{The Creativity-Based Tapiskwan Workshop Approach}

Over the years, Tapiskwan has developed an approach that places art, design and crafts on an equal plane. This emerged over the years through the involvement of a diverse set of participants and collaborators, whose individual expertise and ideas allowed innovative methods to be explored each year (see Figure 8.2). In the first workshops, when working on developing new products, a classic iterative design process was used, which included brainstorming, drawing and sketching ideas before prototyping and making the objects. Designing new products was a central aspect of these workshops in the effort to explore and develop socio-economic opportunities for artists and craftspeople. This focus was also aimed at finding new ways to work around the increasingly limited access to raw materials, such as birch bark or good quality moose skins, both of which are greatly impacted by the forestry industry and environmental change in the area. Thus, an important criterion became the ability to make multiple reproductions of the same item with alternative materials. This shifted the focus to developing graphic designs based on Atikamekw symbolism and to exploring print-based art methods that allowed for the reproduction of imagery on new materials.

After making their new graphic art, participants applied it to various surfaces: framed art pieces, metres of fabric, tote bags, cushions, notebooks and wooden paddles. This approach proved to be quite successful for the ideation process, but more challenging for the actual production of a collection of items, especially at first. The pre-thinking and pre-planning phases of the production process (which designers are trained to do) were not something these craftspeople were accustomed to doing in a formal way; in their regular practice, they do not typically reproduce the exact same item multiple times. Even when they make more than one item at a time, each usually remains unique in one way or another. Their disinterest in line production necessitated reconsidering the degree to which it was feasible and important to standardise production in the perspective of marketing the products. As a result, the lines between 'craft' and 'design' remained blurred.

Moreover, new techniques were tested and explored with participants every year, including linocuts, foam stamps, stencils and silk-screening (see Figure 8.2 for an overview of the creativity-based methods used in the Tapiskwan workshop approach). As the communities in which the Tapiskwan workshops have been held are remote, access to some materials and equipment is limited. Finding new ways to do activities that worked in these settings was a key objective: for instance, making stamps with cardboard and foam found in recycling bins, using inexpensive foam camping pads to turn cafeteria-style tables into makeshift fabric printing stations or finding a way to prepare high-quality silk-screens in the community without access to professional equipment. Although it requires some technical knowledge, silk-screening immediately attracted the interest of the participants as a popular printing method due to its effectiveness for repetition and the quality of prints, mitigating somewhat the previously identified challenge of line production. As far as being a feasible reproduction process, participants found that it struck a nice balance between precision and the freedom to explore. Other printing methods used during the workshops mirrored the 


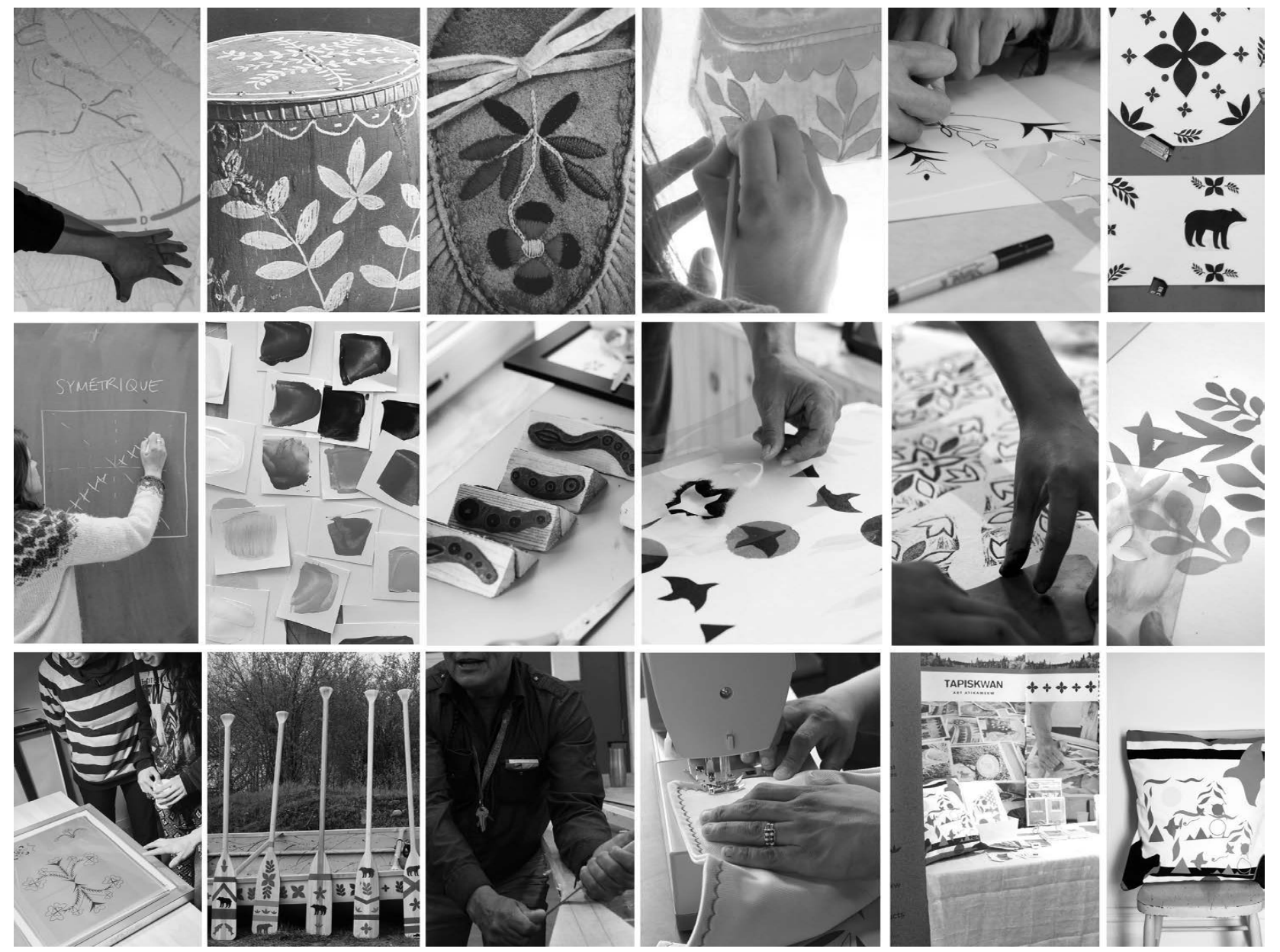

Figure 8.2 Creativity-based methods in the Tapiskwan workshop approach. 


\section{Caoimhe Isha Beaulé et al.}

methods which Atikamekw craftspeople have always used to adorn their work. For example, cut-outs are commonly used to engrave symbols into birch bark, while stencils are often used to draw embroidery patterns on leather. The participating craftspeople were therefore almost instant experts in what were supposedly 'new' creative techniques brought to the table by the designers.

In a workshop that was held for high school students, in addition to the graphic and print-based activities, a second and parallel programme was held in the wood workshop with one of the community's best craftspeople, who knew how to make canoe paddles from scratch. Being able to work with such experienced individuals provided the youth with a particularly motivating setting. The enthusiasm of the professional designer who co-facilitated this workshop, and the positive dynamic between these two mentors, was crucial in that regard. In general, it was a fundamental requirement to involve members of the Atikamekw community in the facilitation process. This helped to further expand the methods being used and developed during the workshops. Especially when working with youth, these mentors could also act as role models and speak in their native tongue. At the same time, the involvement of outsiders who brought their own expertise and were respectful of these community mentors' knowledge and know-how proved a fruitful combination. Although always unique, the Tapiskwan workshop model generally followed this basic structure: 1) intergenerational knowledge transfer by inviting elders, craftspeople, accomplished and emerging artists or entrepreneurs; 2) technical training such as learning new printing techniques or practicing drawing skills; and 3) a definite project to complete by the end of the workshop, such as printed designs, artwork or wood objects. The workshops most often ended with a sale or an exhibition.

The methodological approach developed over the years revealed itself to be the most important outcome of the project. Its success was evident with the high school students who demonstrated an increased attendance, motivation and pride in accomplishing the workshop goals. Moreover, collaborators have often been invited to present the method to other communities or host workshops in various settings. Many Atikamekw mentors and collaborators have also continued using and developing the methods on their own. Previous publications on Tapiskwan have focused on the development of these methodologies (see Leitao et al., 2017; Marchand et al., 2018). Beyond the methodological design approach that was at the heart of the research contributions, the Tapiskwan initiative enabled the forging an identity that advanced the diffusion of Atikamekw art and design, but also helped to create a sense of belonging to the project amongst researchers, collaborators, participants and partners. In fact, these relational bonds that were developed through these intensive creative activities were an unforeseen-yet highly valued-outcome of the project.

\section{Establishing the Basis for Collaboration With Creativity}

In order to successfully develop interpersonal relations through 'making', some foundational elements are needed. Designer/researchers require a set of abilities and mindsets when engaging in projects such as Tapiskwan. They require training in ethical and participatory research practices, particularly if the project involves Indigenous participants. However, learning about these aspects of collaborative design with communities has yet to become a staple of the mainstream design education curriculum. Unfortunately, this type of content is impossible to learn entirely from books. In that 
respect, creativity-based methods can be part of this process of intercultural mediation, insofar as everyone involved is open to engaging in the creative process.

In a project that brings together individuals with diverse backgrounds, not everyone may be comfortable painting, drawing and engaging in any kind of artistic activity. In Tapiskwan, all the participants were encouraged to partake in the creative work, and it was typical for everyone to participate in the workshops' creative activities one way or another, regardless of experience or expertise. Although it was essential to have mentors who had already mastered the techniques being transmitted, it was also important for all the participants to feel welcome to engage in the creative activities. Our organic approach made for an unexpected and unorthodox distribution of roles. Instead of each person keeping to their field of practice, social entrepreneurs could momentarily take on the title of creative director, or an anthropologist could become the assistant of an experienced artist; in fact, an industrial design teacher accustomed to running the show with his students took on the position of an apprentice to an expert craftsman, and a master seamstress mentored students in the art of printmaking. This generalised engagement in creative activities, and the mixing up of roles and responsibilities, allowed for different kinds of relationships to develop amongst participants (Figure 8.3).

While some of the activities were organised according to a more traditional approach (experienced mentors taking inexperienced learners on as mentees), the less traditional redistribution of roles served an important purpose: that of calling into question hierarchies that could have easily been reified. In this more cooperative mindset, the goal was to recognise each person's contribution in terms of knowledge and skills, all the while acknowledging the potential for mutual pollination across levels of expertise as well as the room for growth in each collaborator. The Atikamekw are no strangers to the cooperative approach and to learning to adapt to one's environment and its resources, since both are central to their traditional social organisation and world view (Awashish, 2013). For instance, a participating textile designer learned to adopt a much more do-it-yourself (DIY) approach than what she employed in her own professional workshop, such as using foam camping pads to transform a cafeteria table into a printing station, as mentioned previously. Other participants also demonstrated ingenious initiatives, such as using scrap wood to craft handles for linocut stamps. Both this participant and the textile designer came out of the experience having had to draw on their previous knowledge and existing aptitudes, but each helped the other identify new avenues in their creative process.

Indeed, creativity-based activities in which everyone could engage and learn something new, including those with the most experience in the room, introduced a democratising dynamic into the collaboration. In particular, this forced designers to find a good balance between, on the one hand, sharing their expertise and training participants in new techniques (the task for which they had ostensibly been recruited at the start of the collaboration), and on the other hand, avoiding taking over or imposing a too specific way of doing things. The latter tendency could have easily backfired for two reasons: first, it would have overshadowed the expertise of other partners, and in particular that of community artists, knowledge holders and craftspeople; second, a rigid mindset would have run up against the great need for flexibility in the face of participants' varying levels of engagement and prior experience as well as being challenged by the limited availability of materials and resources. Within such a collaborative dynamic, designers needed to be willing to go outside of their comfort zone, 


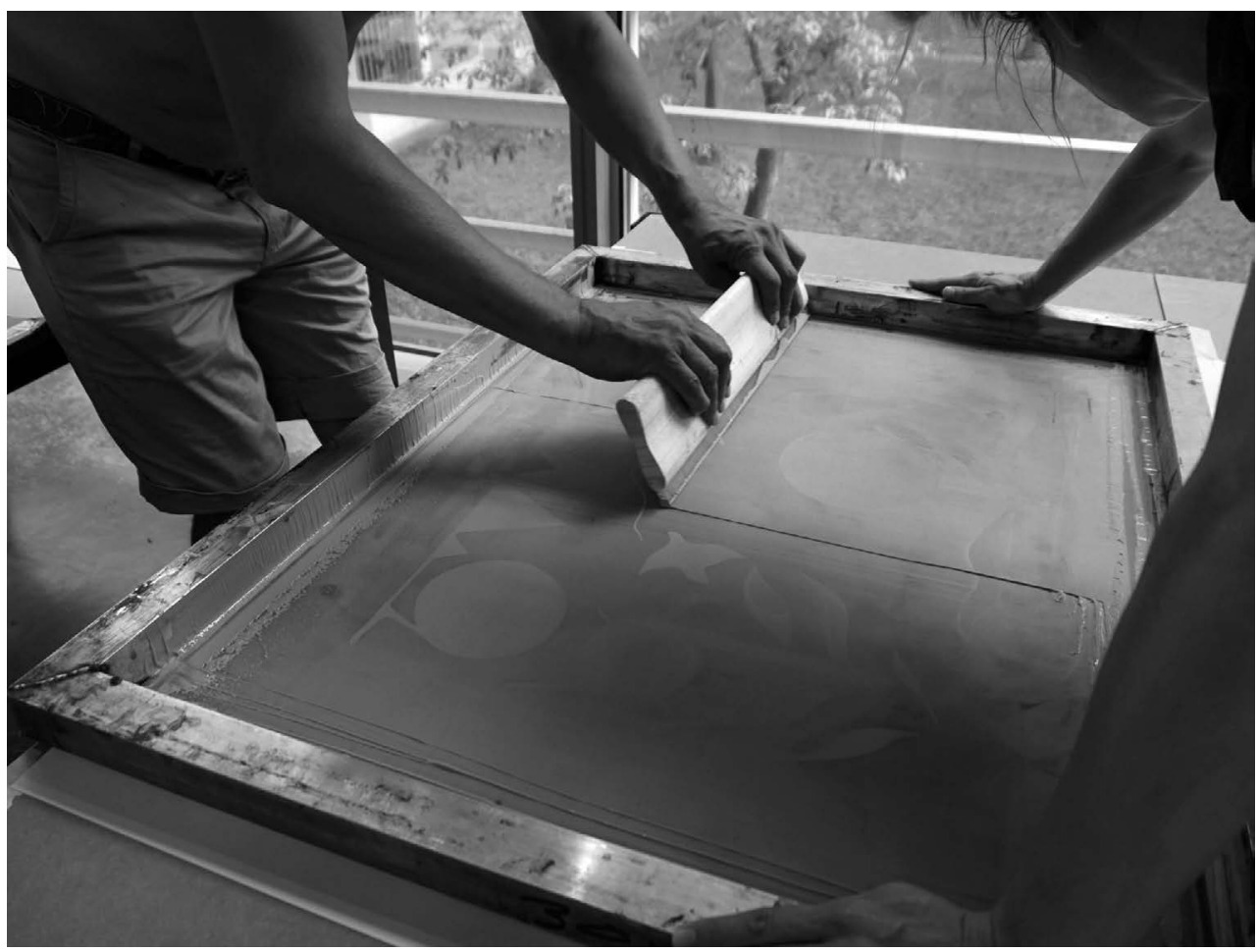

Figure 8.3 Anne Marchand and Atikamekw artist Jacques Newashish printing a large-format piece.

Source: Photo by Collectif Tapiskwan; from a 2018 workshop in Montreal.

question and be critical about their role and assumptions, adopt a 'learning' mindset and be ready to change their plans, as things would inevitably have to be adapted on the ground. Indeed, collaborators need to develop a synergy that promotes contribution and creates conditions that foster the pooling of resources in order to enhance the potential of the communities to take charge of their local and regional development (Awashish, 2013).

Establishing the very basis of the collaboration by using a creativity-based method from the start of the project contributed to alleviating some tensions and unproductive dichotomies within the team, such as the supposed oppositions of design versus craft, tradition versus innovation, trainers versus trainees and experiential knowledge versus formal or expert knowledge. Such co-creative activities strengthened participatory engagement and supported the construction of the collective design process. Indeed, these creativity-based methods helped foster a collaborative dynamic that generally contributed to recognising a diverse set of experiences and the range of expertise amongst the team members, as well as positioning designers as both 'mentors' and 'learners'.

With all of this said, we still must return to the central issue that is at the heart of this book: decolonisation of participatory research through art-based methods. More 
specifically, we need to ask an essential question: What reflections on decolonising participatory practices emerged from our experience as collaborators in the Tapiskwan project? Notwithstanding all of the important teachings the project generated, including those we have shared in this chapter regarding creativity-based activities as a way to build relationships of mutual respect, we believe that it is important to also make explicit what was not decolonial about the project and its structures. The following section discusses some key points about that aspect that should be considered.

\section{Fitting a Circle in a Square: Reflections on Decolonising Participatory Design}

In itself, Tapiskwan's overall objective of perpetuating intergenerational transmission and sharing Atikamekw art and culture in Canada (and the world) goes against the colonial grain by affirming cultural sovereignty and making Indigenous presence on the land more visible. Nonetheless, as mentioned at the beginning of this chapter, we use the term decolonisation carefully and specify that Tapiskwan was not developed with 'decolonising' as an explicitly stated goal. The project having only recently started its transition from a participatory research project to a community-led one, decolonisation could become a more central aspect of Tapiskwan in the future. In the meantime, writing this chapter has allowed us to begin to delve below the surface of this difficult and complex topic. Ultimately, decolonisation requires change on a structural and systemic level. Tapiskwan allows us to investigate some of the challenges and opportunities of addressing colonial models on a micro level. It allowed us to think and learn about the dynamics of university-community collaborations, and how these can be shaped by colonial world views and policies even within a project that attempts not to reproduce them. When discussing this topic, Karine described the experience as 'trying to fit a circle in a square' as the project was developed in Canada's structures and policies that enforce settler colonialism (Côté, 2019). We thought this metaphor summarised some of the obstacles we encountered. With a certain distance from our involvement in the project, we hope to be better able to grasp the structural ins and organisational outs of Tapiskwan's participatory action research framework and how it remains influenced by colonial institutions and state structures, and reflect on what adopting a more deeply decolonial approach would look like in the future.

\section{Limits on the Structural Level: Who Has the Power? Who Has the Money?}

Discussing decolonisation in the context of the Tapiskwan project brings up questions about the leadership and the structural frameworks that limit how much change can happen on the ground. This was reflected, for instance, in the rigid financial structures of research grants. In Canada, the funding agencies address their call for projects to the universities, leaving it up to the researchers to initiate collaborations with community partners. This bureaucratic model does not encourage the process to occur the other way around, setting the stage for issues of power. If the funding agencies created programmes for projects initiated by Indigenous communities themselves, these partnerships would likely look quite different. Furthermore, under the current model, universities are typically the ones managing the research funds. This almost instantly creates a hierarchy of roles by giving greater control to those who hold the financial resources. In Tapiskwan, this was seen as an ongoing obstacle to developing real trust 
with Indigenous collaborators, and often imposed the very same hierarchies that we were trying to challenge in these collaborations. Other challenges encountered in relation to money were those tied to the capitalist market for which we were developing products. For instance, the latter created some production and distribution constraints that were antithetical to community members' practices and upheld Western intellectual property laws rather than Indigenous ones.

Furthermore, projects must include enough time in their timelines to develop their relational activities: 'A decolonising project dwells on time and moves at a different pace' (Schultz et al., 2018, p. 93). As many community-based participatory design research projects exist through funding calls, developing proposals should ideally begin at the very start and in a cooperative way. On a similar note, projects should also involve thinking about the future of the project, such as determining what happens after the funding ends and how the community will benefit from it in the long run. As these participative research projects are often made possible through funding opportunities, they often come with short, fixed timelines. This project existed for several years as a research project before taking on its new identity as a community-run project; this transformation was made possible over time and because there was, in fact, the time to build trust amongst parties and develop strong ties for the collaboration and the transition afterwards.

\section{Decolonisation as an Ongoing Process}

As acknowledged previously, this chapter was principally developed from the perspective of designer/researchers and collaborators who represent only a few of the many individuals engaged in this long-term project. While not all voices in the project are represented here, we wanted to emphasise that there is a need for non-Indigenous individuals to recognise the role they must play in changing things in their own practices and the structures within which they operate. Schultz et al. (2018) highlight that:

Decolonizing design does not aim to create an opposition between 'decolonized' and 'colonized' designers or design practices. Rather, it promotes the ontological changes that will allow us to design more time for ourselves in this world. It is a project of incompleteness, of persistently un-learning and re-learning to see the world. We must constantly interrogate not only the field but also ourselves and our own practice.

Thus, as (mostly) non-Indigenous researchers, we see this still incomplete reflection on decolonisation as a contribution to the process of unlearning and relearning for our future practice (Côté, 2019; Schultz et al., 2018). Karine also reminds us that her perspectives do not represent those of all her community, either. Although our reflections are a crucial part of the equation, we also judge that it would be impossible to truly address the topic of decolonisation in the Tapiskwan project without engaging in profound reflections and dialogues with most of our Atikamekw collaborators. In our discussions, it was also highlighted that Indigenous peoples in Canada are busy (re)developing themselves and that the burden of educating the dominant society on decolonisation must not also be put on them.

Along the same line of thought, we see it as crucial to further locate the Euro-centrism of our own design education, to identify areas that could be challenged in order to acknowledge and deconstruct the unconscious dominance of Western paradigms 
and to acknowledge and include 'design with other names' (Akama et al., 2019, p. 11). Socio-historical realities that have entrenched university-community relationships in colonial and otherwise hierarchical and ethnocentric models are not always explicitly addressed in this type of project, yet they can strongly influence its dynamics and, ultimately, the success of its outcomes. Moreover, exploring new ways to adapt design methods to different cultural settings is essential: for instance, finding ways to value the expertise, skills and knowledge possessed by some of the participants and stakeholders to the same level as the professional designers involved. Designers must be aware of the 'consequences of misplaced enthusiasm for design thinking toolkits for beginners that emphasise a bias for action, without due process and consideration for duty of care, safety or ethics' (Akama et al., 2019, p. 4). We see that using a holistic approach to art, design and crafts within participatory processes allows much more potential, and that it is more appropriate for the work with our Atikamekw collaborators and participants. Looking out to the future, there is still a lot of work to be done:

The challenge for us now, as practitioners, researchers, and educators of design, is to carve out ways for respectful, reciprocal, and relational co-designing for social innovation that is premised upon a pluriversal view.

(Akama et al., 2019, p. 23)

Thus, this chapter merely sets the table for continuing this discussion with more collaborators of the project to delve deeper into this topic of decolonising participatory practices, with Tapiskwan as the starting point.

\section{Conclusion}

To this day, frameworks for designers and design researchers working in communitybased participatory design projects are few and far between. In this sense, we are still entering new areas within the practice of design. The Tapiskwan project has exemplified this well, as many challenges persisted, even within a formalised partnership between a university and a community. However, a methodology that draws on art, design and crafts in a holistic way greatly helped in building relationships that have made the project survive for many years. Considering this, we argue that there is distinct value and potential in such creativity-based methods for developing the relational dimensions of participatory design and collaboratively building a design process and innovative outcomes. With regard to the idea of 'decolonising' participatory research with arts-based-or, in this case, creativity-based-methods, we do believe that Tapiskwan aims to generate such opportunities for transformation by building relationships that challenge hierarchies and by conducting activities that call into question Western ways of knowing and doing. Tapiskwan is indeed shaped by our collective efforts, hand in hand with our Atikamekw partners, to integrate 'meaningful decolonial practices, strategies, and sensibilities' into our approach (Roth, 2019, p. 308). However, this does not, in our view, make the project an example of a fully 'decolonised' endeavour, as we acknowledge that some significant colonial biases and the several limitations of colonial structures have affected the project in significant ways. Moving forward, our hope is to find ways to carry with us the lessons we learned about the power of creativity-based methods and the relationships we built, thanks to these methods, to further contribute to the decolonisation efforts of our community partners. 


\section{Acknowledgements}

We would first like to thank all our collaborators and teammates involved in the Tapiskwan project. The first author would like to thank and acknowledge the Fonds de Recherche du Québec and the Finnish National Agency for Education (through the EDUFI fellowship) for financially supporting her ongoing doctoral studies. The Tapiskwan project was supported in part by funding from the Social Sciences and Humanities Research Council of Canada and the Fonds de Research du Québec. The authors are also thankful to the Trans-Atlantic Platform for the Social Sciences and Humanities for the financial assistance to the project 'SEEYOUTH: Social Innovation through Participatory Art and Design with Youth at the Margins', which provides a positive and encouraging environment for discussions.

\section{References}

Akama, Y., Hagen, P., \& Whaanga-Schollum, D. (2019). Problematizing replicable design to practice respectful, reciprocal, and relational co-designing with indigenous people. Design and Culture, 11(1), 59-84.

Awashish, K. (2013). Économie sociale en contexte autochtone: la création d'une coopérative d'artisanat atikamekw [Social economy in an Indigenous context: The creation of an Atikamekw crafts cooperative] [Master's thesis, Université du Québec à Trois-Rivières].

Barone, T., \& Eisner, E. W. (2011). Arts based research. SAGE Publishing.

Bason, C. (2016). Design for policy. Routledge.

Battiste, M., \& Youngblood Henderson, J. (2000). Protecting indigenous knowledge and heritage: A global challenge. Purich Publishing Ltd.

Brown, T., \& Katz, B. (2009). Change by design: How design thinking transforms organisations and inspires innovation (1st ed.). Harper Business.

Côté, I. (2019). Théorie postcoloniale, décolonisation et colonialisme de peuplement: Quelques repère pour la recherche en français au Canada [Postcolonial theory, decolonisation and settlement colonialism: Some benchmarks for research in French in Canada]. Cahier FrancoCanadiens de l'ouest. L'autochtonisation pour préparer un avenir commun, 31(1), 25-42. www.erudit.org/fr/revues/cfco/2019-v31-n1-cfco04515/1059124ar/

Design Council UK. (2005). The design process. Design Council UK. www.designcouncil.org. uk/sites/default/files/asset/document/ElevenLessons_Design_Council\%20(2).pdf

Dorst, K. (2011). The core of 'design thinking' and its applications. Design Studies, 32(6), 521-532.

Dorst, K. (2019). Co-evolution and emergence in design. Design Studies, 65, 60-77.

Escobar, A. (2018). Designs for the pluriverse: Radical interdependence, autonomy, and the making of worlds. Duke University Press.

Gaver, B., Dunne, T., \& Pacenti, E. (1999). Design: Cultural probes. Interactions, 6(1), 21-29.

Gélinas, C. (2003). Entre l'assommoir et le godendart: Les atikamekw et la conquête du MoyenNord québécois 1870-1940 [The Atikamekw and the conquest of Quebec's Middle North 1870-1940]. Sillery: Les Éditions du Septentrion.

Guttorm, G. (2015). Contemporary duodji: A personal experience in understanding traditions. In T. Jokela \& G. Coutts (Eds.), Relate north: Art, heritage, \& identity (pp. 60-77). Lapland University Press.

Janzer, C. L., \& Weinstein, L. S. (2014). Social design and neocolonialism. Design and Culture, 6(3), 327-343.

Jokela, T., Huhmarniemi, M., \& Hautala-Hirvioja, T. (2019). Preface. In M. Huhmarniemi, T. Jokela, \& T. Hautala-Hirvioja (Eds.), Arctic arts in the time of change (pp. 6-11). University of Lapland.

Kaine, É. (2018). Introduction: Design et culture matérielle: Récits de savoirs partagés par l'art et la création en milieux autochtones [Design and material culture: Stories of knowledge 
shared through art and making in Indigenous environments]. Recherches amérindiennes au Québec, 48(1-2), 5-9. https://doi.org/10.7202/1053698ar

Kaine, É., De Coninck, P., \& Bellemare, D. (2010). Pour un développement social durable des individus et des communautés autochtones par la recherche action/création: Le design et la création comme leviers de développement [For a sustainable social development of individuals and Indigenous communities through action/creative research: Design and making as levers of development]. Nouvelles Pratiques Sociales, 23(1), 33-52. https://doi. org/10.7202/1003166ar

Kaine, É., De Coninck, P., Bergeron-Martel, O., \& Bellemare, D. (2016). The little guidebook on the extensive consultation: Cultural creation and transmission by and with communities. Les Presses de l'Université Laval.

Kovach, M. (2010). Indigenous methodologies: Characteristics, conversations, and contexts. University of Toronto Press.

Lamothe, B. (1999). Vie quotidienne et adaptation des atikamekw de Wemotaci à la modernité [Daily life and adaptation of the Atikamekw of Wemotaci to modernity]. Groupe de Recherche Hypothèse Inc.

Leavy, P. (2015). Method meets art: Arts-based research practice. Guilford Publications.

Leavy, P. (Ed.). (2018). Handbook of arts-based research. Guilford Publications.

Leitao, R. M., Sportes, C., Marchand, A., \& Roth, S. (2017). Tapiskwan project: A design approach to foster empowerment among Atikamekw artisans. The International Journal of Design in Society, 11(4), 17-32.

Lonetree, A. (2012). Decolonizing museums: Representing Native America in national and tribal museums. University of North Carolina Press.

Mäkiranta, M., \& Ylitapio-Mäntylä, O. (2019). Engaging ethics of care in socially responsible design and in research projects with Indigenous communities. In S. Miettinen \& M. Sarantou (Eds.), Managing complexity and creating innovation through design (pp. 36-46). Routledge.

Marchand, A., Awashish, K., Coocoo, C., Roth, S., Leitão, R. M., Sportes, C., \& Beaulé, C. I. (2018). Culture as a resource for a sustainable future in indigenous communities. Design Roots: Local Products and Practices in a Globalized World, 131-146.

Miettinen, S., Sarantou, M., \& Akimenko, D. (2016). Art and storytelling as an empowering tool for service design: South Australian case study. In P. Rytilahti \& S. Miettinen (Eds.), For profit, for good: Developing organisations through service design (pp. 74-80). University of Lapland.

Nelson, H. G., \& Stolterman, E. (2012). The design way: Intentional change in an unpredictable world (2nd ed.). The MIT Press.

Roth, S. (2019). Can capitalism be decolonized? Recentering indigenous peoples, values, and ways of life in the Canadian art market. The American Indian Quarterly, 43, 306-338.

Sanders, E. B. N., \& Stappers, P. J. (2008). Co-creation and the new landscapes of design. CoDesign, 4(1), 5-18.

Schultz, T., Abdulla, D., Ansari, A., Canlı, E., Keshavarz, M., Kiem, M., Martins, L. Prado de O., \& Vieira de Oliveira, P. J. S. (2018). What is at stake with decolonizing design? A roundtable. Design and Culture, 10(1), 81-101.

Smith, L. T. (2012). Decolonizing methodologies: Research and indigenous peoples (2nd ed.). Zed Books Ltd.

Tlostanova, M. (2017). On decolonizing design. Design Philosophy Papers, 15(1), 51-61.

Truth \& Reconciliation Commission of Canada. (2015). Canada's residential schools: The final report of the Truth \& Reconciliation Commission of Canada (Vol. 1). McGill-Queen's Press-MQUP.

Tuck, E., \& Yang, K. W. (2012). Decolonization is not a metaphor. Decolonization: Indigeneity, Education \& Society, 1(1), 1-40.

Tunstall, E. (2013). Decolonizing design innovation: Design anthropology, critical anthropology, and indigenous knowledge. In W. Gunn, T. Otto, \& R. C. Smith (Eds.), Design anthropology: Theory and practice (pp. 232-250). A\&C Black. 